\title{
A PROMOÇÃO DA JUSTIÇA AMBIENTAL NO CONTEXTO DA DESIGUALDADE SOCIAL BRASILEIRA
}

\section{Keit Diogo Gomes*}

RESUMO: O estudo propõe-se a analisar a justiça ambiental em um contexto de desigualdades sociais na sociedade brasileira. $\mathrm{O}$ mesmo será construído em três seções. O primeiro capítulo é destinado a teoria da justiça ambiental, explicitando o conceito de justiça e injustiça ambiental, contexto histórico e casos sociais que impulsionaram o surgimento da teoria. Em sequência apresenta-se a equidade geográfica, correlacionando pobreza e ônus ambiental. A terceira seção expõe os destinatários da tutela ambiental, por meio de três vieses: o intergeracional, o intrageracional e o interespécies. A pesquisa foi primordialmente bibliográfica, servindo-se do método qualitativo-dedutivo para análise de dados.

PALAVRAS-CHAVE: Justiça. Meio Ambiente. Desigualdade. Exclusão. Ambiental.

\section{THE DEVELOPMENT OF ENVIRONMENTAL JUSTICE IN THE CONTEXT OF BRAZILIAN SOCIAL INEQUALITY}

\begin{abstract}
The study proposes to analyze environmental justice in a context of social inequalities in Brazilian society. The same will be built in three sections. The first chapter is devoted to the theory of environmental justice, explaining the concept of justice and environmental injustice, historical context and social cases that gave rise to the theory. Geographic equity is presented in sequence, correlating poverty and environmental burden. The third section exposes the recipients of environmental protection, through three biases: intergenerational, intragenerational and interspecies. The research was primordially bibliographical, using the qualitative-deductive method for data analysis.
\end{abstract}

KEYWORDS: Justice. Environment. Social Inequality. Exclusion. Environmental.

\footnotetext{
* Professora na Universidade Federal de Mato Grosso e advogada. Mestra em Direito Agroambiental e especialista em Direito Penal e Processual Penal.
} 


\section{INTRODUÇÃO}

O presente artigo propõe-se a abordar a realização de uma efetiva justiça ambiental na sociedade brasileira, notadamente marcada por desigualdades e exclusões sociais para com determinados grupos de indivíduos.

O Brasil enquanto país em desenvolvimento não conseguiu garantir aos cidadãos o acesso regular aos direitos sociais necessários a uma vida digna. Considerando as discrepâncias existentes no campo social, o que interferiu também na concretização da proteção de seus bens jurídicos ambientais, motivo pelo qual a necessidade da ampla promoção da justiça ambiental para com uma sociedade socialmente desigual, mostra-se necessária.

Com este escopo o estudo apresenta inicialmente a teoria da justiça ambiental. Sendo necessário valer-se de sua compreensão histórica, a apresentação de uma definição de justiça ambiental e de seu antagonista: a injustiça ambiental, bem como delinear de forma introdutória sua correlação com os movimentos sociais.

O segundo capítulo da pesquisa conduz o leitor a compreender a denominada equidade geográfica. É neste ambiente que será verificado se o ônus ambiental é direcionado geograficamente a grupos sociais considerados excluídos ou marginalizados, abordando ainda conceitos como desigualdade e exclusão social.

No terceiro tópico, os beneficiários da tutela jus ambiental serão identificados, com vistas a perquirir de qual maneira, cada um destes destinatários poderá ser favorecido pelos movimentos por justiça ambiental e/ou contribuir de forma significativa para sua promoção em respeito as futuras gerações, e, demais espécies vivas.

Por derradeiro será apresentado uma interligação dos tópicos analisados, com finalidade de apurar se o movimento por justiça ambiental pode ser traçado de forma autônoma aos direitos sociais. Ademais, será possível observar de quais maneiras a promoção pela justiça ambiental pode influenciar na participação dos mais variados grupos de beneficiários.

O estudo ora apresentado pauta-se pela pesquisa bibliográfica, tendo ainda se servido do método de abordagem qualitativo e dedutivo de análise de dados. 


\section{JUSTIÇA AMBIENTAL}

A demanda por justiça ambiental invariavelmente está relacionada a divisão de determinados grupos sociais, que uma vez marginalizados, tendem a ficar vulneráveis no cenário social e, portanto, tendem a tornar-se sujeitos passivos da violação dos direitos ambientais de forma menos evidente.

É por isto que a teoria da justiça ambiental parte do pressuposto que as lutas ambientais e sociais devem ser abordadas de forma conjunta, buscando minimizar o ônus desproporcional dos riscos e danos ambientais para com populações sociais menos favorecidas.

O movimento por justiça ambiental originou-se nos Estados Unidos, aproximadamente em 1960, com escopo de refutar a exposição a contaminações tóxicas a que estavam expostas as comunidades habitadas por pessoas pobres e imigrantes. Os locais habitados preferencialmente por negros, pobres e imigrantes, estavam sujeitos a receber um percentual superior de depósitos de lixos tóxicos (RAMMÊ, 2012, p. 14).

O contexto social que culminou com os movimentos sociais em questão, está registrado por Henri Acselrad (ACSELRAD. 2002, p.49):

O Movimento de Justiça Ambiental constituiu-se nos EUA a partir de uma articulação criativa entre lutas de caráter social, territorial, ambiental e de direitos civis. Já a partir do final dos anos 60, redefiniu-se em termos "ambientais" um conjunto de embates contra as condições inadequadas de saneamento, de contaminação química de locais de moradia e trabalho e disposição indevida de lixo tóxico e perigoso. Foi então acionada a noção de eqüidade geográfica, como "referente à configuração espacial e local de comunidades em sua proximidade a fontes de contaminação ambiental, instalações perigosas, usos indesejáveis do solo como depósito de lixo tóxico, incineradores, estações de tratamento de esgoto, refinarias etc. Nos anos 70, sindicatos preocupados com saúde ocupacional, grupos ambientalistas e organizações de minorias étnicas articularam-se para elaborar em suas respectivas pautas o que entendiam por "questões ambientais urbanas". Alguns estudos apontavam já a distribuição espacialmente desigual da poluição segundo a raça das populações a ela mais expostas, sem, no entanto, que se tivesse conseguido, a partir das evidências reunidas, mudar a agenda pública. 
Alguns dos principais movimentos registrados podem ser citados: a) love canal (Estado de Nova York - Estados Unidos) ${ }^{1}$; b) Caso de Afton - racismo ambiental ${ }^{2}$; c) memorando Summers ${ }^{3}$; d) o caso da cidade dos meninos (Duque de Caxias - Rio de Janeiro) ${ }^{4}$.

Para além da contribuição norte-americana com a promoção dos direitos socioambientais, Alíer Martínez destaca que esta preocupação se encontrava presente na pauta dos ativistas por meio do ecologismo popular, também denominado ecologismo dos pobres conjuntamente com outras discussões ambientais.

"Verificam-se três correntes relativas à preocupação e ativismo ambientais:

- O "culto ao silvestre" ou à "vida selvagem", preocupado com a preservação da natureza silvestre, sem se pronunciar sobre a indústria ou a urbanização, mantendo-se indiferente ou em oposição ao crescimento econômico, muito preocupado com o crescimento populacional e respaldado cientificamente pela biologia conservacionista.

\footnotetext{
${ }^{1}$ O caso Love Canal desencadeou-se na cidade de Niágara Falls, Estado de New York nos Estados Unidos. Sua história remonta ao ano de 1892, neste ano, William T. Love pretendia conectar as partes alta e baixa do rio Niágara, abrindo um canal de cerca de $9,6 \mathrm{~km}$ de extensão e 85 metros profundidade. O projeto foi abandonado por volta de 1920 e a área foi vendida, tornando-se um depósito de lixo até o ano de 1953. Uma das principais empresas que lá depositavam seus dejetos era a Hooker Chemical Corporation, mas também a cidade de Niagara Falls e o Exército norte-americano usaram o local como despejo. Após sua utilização como depósito de dejetos, a área foi coberta de terra. Neste mesmo período, na década de 50, a área no entorno do canal começou a ser urbanizada, com a construção de moradias, bairros e, inclusive com a instalação de uma escola primária em 1955. Somente por volta da década de 70 , com a crescente desenvolvimento de casos de doenças e contaminações nas crianças locais, a comunidade local descobre que suas casas foram erguidas sobre o aterro do canal, que continha uma variedade de dejetos químicos industriais e materiais bélicos variados (HERCULANO, 2001, p.215-238).

${ }^{2} \mathrm{O}$ caso de Afton é considerado por muitos teóricos, o marco principal a delinear a atuação dos movimentos por justiça ambiental. No ano de 1982, na cidade de Afton, no condado de Warren County, estado da Carolina do Norte, cerca de $60 \%$ da população local dos 16 mil habitantes da época, era composta por afroamericanos, vivendo em situação de extrema pobreza. O governo local, sem consulta prévia, decidiu implantar na região um depósito para resíduos de policlorobifenilos (PCB).

${ }^{3}$ O memorando se tornou público em 1991, nele o economista Lawrence Summers apresenta três argumentos para que os países em desenvolvimento (pobres) fossem o destino dos depósitos industriais de grande impacto ambiental. O primeiro argumento para tal assertiva, assenta-se na premissa de que a preocupação com o meio ambiente é meramente "estética" e naturalizada por países ricos. A segunda premissa sustenta que os indivíduos mais pobres não têm a mesma expectativa de vida, a ponto de sofrer os efeitos da poluição ambiental (ACSELRAD. Henri. 2002, p. 08).

${ }^{4}$ A Cidade dos Meninos cuida-se de um complexo de origem do governo de Getúlio Vargas no ano de 1938, desenvolvido na baixada fluminense, especificamente no município de Duque de Caxias - RJ, com a finalidade de abrigar, em regime de internato, menores para que fossem educados e profissionalizados. Em 1949, Mário Pinotti, diretor do antigo Serviço Nacional de Malária do então único Ministério de Educação e Saúde, recebeu o direito de utilizar 8 pavilhões da Cidade dos Meninos, para a introdução do Instituto de Malariologia, voltado ao tratamento de malária. Ainda em 1949, o instituto de saúde começa a produzir no local o inseticida BHC, vulgarmente denominado pó-de-broca, ou hexaclorociclohexano $(\mathrm{HCH})$, um composto de benzeno. A produção do composto durou anos e após se tornar inviável manter a sua fabricação, foi abandonado sem qualquer precaução com a segurança local dos meninos que residiam na Cidade, e dos demais moradores de seu entorno. A mídia, na época, apontava cerca de 300 a 350 toneladas de pó-de-broca que foram abandonados. O processo de desativação da fábrica não foi controlado e seus maquinários, móveis e estoques de $\mathrm{HCH}$, bem como matérias-primas, foram ignorados. (HERCULANO, Selene. Ano, p.228 ).
} 
- O "credo da ecoeficiência", preocupado com o manejo sustentável ou "uso prudente" dos recursos naturais e com o controle da contaminação, não se restringindo aos contextos industriais, mas também incluindo em suas preocupações a agricultura, a pesca e a silvicultura. Essa corrente se apoia na crença de que as novas tecnologias e a "internalização das externalidades" constituem instrumentos decisivos da modernização ecológica. Essa vertente está respaldada pela ecologia industrial e pela economia ambiental.

- O movimento pela justiça ambiental, o ecologismo popular, o ecologismo dos pobres, nascidos de conflitos ambientais em nível local, regional, nacional e global causados pelo crescimento econômico e pela desigualdade social. Os exemplos são os conflitos pelo uso da água, pelo acesso às florestas, a respeito das cargas de contaminação e o comércio ecológico desigual, questões estudadas pela ecologia política. Em muitos contextos, os atores de tais conflitos não utilizam um discurso ambientalista. Essa é uma das razões pelas quais a terceira corrente do ecologismo não foi, até 1980, plenamente identificada. Assim, este livro analisa tanto injustiças ambientais que completaram um século de existência quanto aquelas que ocorreram há poucos meses. (MARTÍNEZ, 2007, p. 38/39)"

A promoção de direitos socioambientais está umbilicalmente conectada com a justiça ambiental/social, tendo em vista que suas demandas são correlatas. A precariedade de cuidados na esfera social com determinada grupo populacional, historicamente tem evidenciado uma violação intensificada de seus direitos ambientais, acarretando um passivo ambiental deveras oneroso a esta população carente de recursos financeiros.

A justiça ambiental é um postulado que visa garantir a fruição igualitária dos bens ambientais e a justa distribuição dos ônus decorrentes da exploração do meio ambiente, a busca por este ideal deve ocorrer com a participação de toda a comunidade em caráter nacional e transnacional.

\subsection{Injustiça Ambiental}

Proclamar a necessidade de justiça ambiental decorre diretamente da existência de seu antagonista, qual seja: a injustiça ambiental. Apontam-se duas definições de injustiça ambiental formulados por Rogério Rammê (2012, p.38):

Injustiça Ambiental passou a designar o fenômeno da destinação da maior carga dos danos ambientais decorrentes do processo de desenvolvimento a certas comunidades tradicionais, grupos de trabalhadores, grupos raciais discriminados, populações pobres, marginalizadas e vulneráveis

E ainda:

O conceito de injustiça ambiental conduz à percepção de que a desigualdade social acaba expondo a sociedade também de forma desigual aos riscos da poluição e degradação ambiental. Em outras palavras: a vulnerabilidade social, econômica e 
política das camadas menos favorecidas da população faz com que sobre elas recaiam, diretamente, os riscos e conseqüências do modelo econômico de desenvolvimento reinante na era do hiperconsumo (RAMMÊ. 2012, p. 38).

A injustiça ambiental está direcionada a distribuição do ônus decorrente das degradações ambientais, ou atividades tipicamente poluentes que são direcionadas para áreas em que persistem os bolsões de pobreza, acabando por prejudicar de maneira acentuada as populações que sequer são beneficiadas com o modelo desenvolvimentista/capitalista.

Essa postura é verificada no âmbito nacional, quando o país desloca seu lixo tóxico e focos de degradação a áreas mais pobres ou menos desenvolvidas tecnologicamente, ou ainda, numa perspectiva global, quando países desenvolvidos, adquirem áreas em países ainda em desenvolvimento, para o fim de escoar o lixo e resíduos tóxicos.

Henri Acselrad definiu a injustiça ambiental, tomando, por base, os postulados da Rede Brasileira de Justiça Ambiental, a saber:

Definiu-se então por injustiça ambiental o mecanismo pelo qual sociedades desiguais, do ponto de vista econômico e social, destinam maior carga dos danos ambientais do desenvolvimento às populações de baixa renda, aos grupos raciais discriminados, aos povos étnicos tradicionais, aos bairros operários, às populações marginalizadas e vulneráveis. (ACSELRAD. 2009, p. 41)

Algumas das principais causas que contribuem para a promoção da injustiça ambiental, por meio da denominada desigualdade ambiental são mencionadas por Acselrad. São quatro os indicadores: a) Mercado: o fato das classes financeiramente favorecidas conseguirem esquivarse das áreas de maiores riscos ambientais, residindo em áreas que gozam de maior grau de proteção; b) Políticas: algumas políticas governamentais ou omissão do Estado tendem a acarretar que empreendimentos degradadores ou de infraestrutura perigosas se instalem, preferencialmente, em áreas residenciais de populações de baixa renda.

c) Desinformação: manter a população "às cegas" acerca dos riscos que envolvem certos empreendimentos e ocultação do que será desenvolvido na área, são meios de manter ocultos os riscos produzidos para a comunidade; d) Neutralização das críticas: com finalidade de evitar mobilização popular, algumas empresas desenvolvem atividades ou criam instalações para angariar a simpatia coletiva, investindo em infraestrutura social em bairros periféricos, tais como: construção de creches, postos de saúde, serviços assistenciais, dos quais o Estado tem se omitido.

Conjugando estes fatores, apresenta-se, então, a desigualdade ambiental sob o viés de Henri Acselrad: 


\begin{abstract}
A desigualdade ambiental pode manifestar-se tanto sob a forma de proteção ambiental desigual como de acesso desigual aos recursos ambientais. A proteção ambiental é desigual quando a implementação de políticas ambientais - ou a omissão de tais políticas ante a ação das forças do mercado - gera riscos ambientais desproporcionais, intencionais ou não intencionais, para os mais carentes de recursos financeiros e políticos: os mais pobres, os moradores de áreas desvalorizadas e etnias marginalizadas. Se há diferença nos graus de exposição das populações aos males, isso não decorre de nenhuma condição natural, determinação geográfica ou casualidade histórica, mas de processos sociais e políticos que distribuem de forma desigual a proteção ambiental. (ACSELRAD. 2009, p. 73)
\end{abstract}

O atual cenário de injustiça ambiental de acordo com Roberta Baggio trata-se de uma peculiaridade da sociedade hodierna, em razão do esgotamento dos recursos ambientais, pautados na forma de exploração do mercado:

\begin{abstract}
A produção de injustiças ambientais é um fato peculiar das sociedades contemporâneas, que reflete culturalmente o tipo de relação estabelecida entre seres humanos e natureza. A possibilidade de identificação desse tipo de injustiç está vinculada à chamada crise ambiental, anunciada, principalmente, pela percepção do esgotamento dos recursos naturais diante de um modo de vida sustentado pelo binômio capitalista da produção e do consumo. O desvelamento dessa crise tem colocado a questão da proteção da natureza como um dos principais desafios da atualidade. (BAGGIO, 2014, p. 99)
\end{abstract}

Superar o atual estágio de desigualdade ambiental, que fomenta a injustiça ambiental, não é tarefa fácil. É necessária uma intervenção efetiva do Estado na promoção do meio ambiente sustentável. Inibir a forte intervenção dos agentes econômicos na degradação ambiental será complexo, porém, imprescindível para fins de elidir a deslocação de empreendimentos de risco para populações periféricas. A intervenção popular na tomada de decisões de cunho ambiental, associada à manifestação continuada de uma intervenção na via política e democrática do país é outro fator essencial para a superação das injustiças.

\title{
2 EQUIDADE GEOGRÁFICA E O SISTEMA DE DESIGUALDADE SOCIAL
}

A ausência de condições igualitárias entre as camadas sociais não pode ser invocada como justificativa para abandonar a temática da promoção da justiça ambiental, antes pelo contrário, deve atuar de maneira a minimizar as mazelas já existentes em nosso contexto social. Eis aí a necessidade de intervenção, conforme pontuado por Patrícia Arzabe (2015, não paginado): 
As discussões acadêmicas e políticas vêm proliferando neste campo, após se verificarem que as questões de gênero, de raça, de origem, de idade, todas constituintes de problemas sociais de séria gravidade convergem ao problema da pobreza e da desigualdade econômica. É nestas circunstâncias que mulheres, negros, índios, velhos, crianças, deficientes, migrantes e imigrantes compartilham em geral de desigualdades comuns à carência econômica e não raro à pobreza absoluta: a desigualdade de saúde, de moradia, de ocupação social, de bem-estar e, traço comum, a desigualdade política. A pobreza, nas suas feições de desigualdade de renda e de acesso a recursos, repercute claramente na participação política. Barreiras efetivamente sólidas se acumulam, obstando a participação na democracia e aprofundando os problemas que fazem dissolver a integração social.

O conceito de exclusão social ganhou destaque por volta de 1980. A exclusão social é complexa, e, abarca muito mais que a pobreza e as desigualdades sociais, visto que compreende a construção de todos os espaços de segregação dos quais o indivíduo encontra-se distanciado, em razão de suas condições. Neste sentido é a valiosa contribuição de Patrícia Arzabe (2015, não paginado):

\begin{abstract}
Se o termo pobreza pode ser construído a partir da definição que recebe, incluindo ou deixando de incluir grupos sociais, o termo recente 'exclusão social', ainda que tenha significação certamente difusa e polimorfa, tem o condão de iluminar justamente o espaço social, jurídico e político perdido frente ao estado de destituição de recursos de toda espécie - econômicos, sociais, jurídicos, culturais. A destituição se apresenta como um monstro tentacular, absorvendo qualquer possibilidade de atuação no espaço social às pessoas pobres, grupo em que se incluem as mulheres, os negros, deficientes, índios, velhos, crianças - e todos aqueles que não conseguem partilhar do controle do poder social. O estado de exclusão social oblitera a tal ponto esse espaço que mesmo a capacidade de insurgência e de organização contra os mecanismos que o originam são mirrados.
\end{abstract}

Boaventura de Sousa Santos discorre acerca da desigualdade e exclusão social: " $A$ desigualdade implica em um sistema hierárquico de integração social. Quem está em baixo está dentro e a sua presença é indispensável. Ao contrário, a exclusão assenta num sistema igualmente hierárquico mas dominado pelo princípio da segregação: pertence-se pela forma que se é excluído" (SANTOS. 2010. p 158).

A desigualdade é um sistema intermediário, não tão drástico quanto a exclusão que implica em segregação, porém, importa em uma inclusão seletiva, dada apenas a indispensabilidade das atividades desenvolvidas, não se cuidando de valor intrínseco ao indivíduo.

Como forma de facilitar a compreensão da distinção entre exclusão e desigualdade aponta-se (SANTOS. 2010. p 256):

À medida que os direitos de cidadania foram sendo conferidos às mulheres e elas foram entrando no mercado de trabalho, foram passando do sistema de exclusão para 
o da desigualdade. Foram integradas pelo trabalho, mas os seus salários continuaram até o presente a ser inferiores aos dos homens.

As políticas públicas implementadas por variados governos desde a promulgação da Constituição não conseguiram erradicar a pobreza ou a miséria, embora tenham surtido algum avanço. Sobre a insuficiência de normas jurídicas para resolver o problema, alerta a ministra Cármen Lúcia (2014. p. 07):

\begin{abstract}
Não é novo, nem mesmo raro, que constituições traduzam excelentes propostas, mas não sejam capazes de concretizar os projetos dos povos que as formulam. Ou talvez sejam mesmo os povos, seus autores, que não as conseguem concretizar. Na América Latina, particularmente, tem sido uma constante ter-se a norma, mas não a sua aplicação, o seu acatamento, a sua observância, especialmente pelos governantes, caudilhos com gana de poder e ojeriza a limites, mais ainda a direitos.
\end{abstract}

Alguns dos principais fatores apontados para justificar o sistema de desigualdades e exclusões sociais no Brasil é condenar os fatores históricos como: a colonização portuguesa, o sistema de distribuição de propriedades (sesmarias) no império; a escravidão, a ditadura, a corrupção que impregna os governos, a alta taxa de desemprego, a crise econômica ${ }^{5}$, a baixa escolaridade e altas taxas de analfabetismo, a supervalorização de algumas profissões, taxas de tributação elevada, dentre outros. Todos estes fatores contribuem sobremaneira para a atual desigualdade existente, todavia, enumerá-los, embora auxiliem a compreensão da extensão do dano, não ilustra a saída para sua suplantação. Nesta esteira, Patrícia Arzabe (2015, não paginado):

\begin{abstract}
Em virtude disso, conclui-se que a pobreza e a exclusão não surgem por geração espontânea e não constituem situações estáticas e autoreferenciadas, mas são resultado do modo de relação entre pessoas e grupos. A situação econômica desfavorável de uma pessoa ou de um grupo maior ou menor de pessoas se dá em virtude da natureza das relações presente numa sociedade e pelas racionalidades que a dominam, em especial quando presentes mecanismos e práticas de exploração econômica, social e cultural. Tais mecanismos se verificam concomitantemente nas três esferas e se acham entranhados na sociedade a ponto de serem considerados padrões normais de relacionamento entre os grupos, dificultando a transformação social e a emancipação pessoal de cada um desses membros submetidos ou excluídos.
\end{abstract}

Além do crítico sistema de desigualdades e exclusão social em solo brasileiro, a população marginalizada ainda é submetida a constantes violações de direitos não só de ordem

\footnotetext{
${ }^{5}$ O sociólogo Jessé Souza tem se ocupado em sua obra Ralé Brasileira: quem é e como vivem, dentre outras abordagens, a combater o fetichismo do progresso econômico, ao deliberar que os brasileiros têm uma fé cega de que a expansão do mercado vai libertar o país das desigualdades existentes.
} 
social, mas também na categoria ambiental, tal qual ressalvado até aqui. A ocorrência desta sistemática ocorrência gerou a definição da assim denominada Equidade Geográfica:

[Refere-se] à configuração espacial e locacional de comunidades em sua proximidade a fontes de contaminação ambiental, instalações perigosas, usos do solo localmente desejáveis, como depósitos de lixo tóxico, incineradores, estações de tratamento de esgoto, refinarias etc. (ACSELRAD, Henri. 2009, p. 25)

A abordagem das demandas ambientais não poderá ser analisada de forma isolada do contexto social, pois os fatores sociais estão conectados com a real promoção da proteção dos bens ambientais seja para garantir o acesso aos bens ambientais aos indivíduos segregados ou para garantir que estes, possam suplantar suas necessidades básicas e comprometer-se com a proteção ambiental. Tal como salientado por Mahalia

\begin{abstract}
A partir das análises de conflito, vulnerabilidade e problema ambiental, é possível constatar que os três temas estão diretamente ligados, funcionando como um ciclo, uma vez que esses eventos decorrem normalmente da situação socioambiental presente em uma determinada sociedade, sendo considerados suas particularidades. Há várias condições para que um conflito ocorra, dentre eles, é válido destacar, a condição de vulnerabilidade que se encontra uma parcela dessa sociedade. Essa vulnerabilidade ocorre quando o Estado se mostra ausente (onde negligencia melhores condições a uma parcela da população) ou quando as intenções do capital promovem a entrada destes habitantes, para uma área (pressão imobiliária) onde normalmente apresentam riscos eminentes. (AQUINO. Mahalia. 2014, não paginado)
\end{abstract}

Considerando a atual sistemática de desigualdade e exclusão na sociedade brasileira, a regulação dos problemas sociais é um imperativo para que a promoção da justiça ambiental e a proteção dos bens jurídicos ambientais possam ganhar destaque no cenário nacional. Permitir a manutenção da segmentação social tal como delineado em nosso país, é um constante lembrete dos entraves que precisam ser superados para a efetiva promoção dos direitos socioambientais.

\title{
3 OS BENEFICIÁRIOS DA TUTELA JUS AMBIENTAL
}

O movimento por justiça socioambiental destina-se primordialmente a defender o equilíbrio no uso dos recursos ambientais e distribuição de seu ônus de forma equânime, primordialmente no contexto contemporâneo. Todavia, a prerrogativa da justiça ambiental não se restringe a este viés, encampando, ainda, a proteção aos futuros destinatários dos bens ambientais: as futuras gerações. Nesta esteira, cabe apresentar quem são os destinatários da denominada justiça ambiental. 
Será apontado a seguir o enfoque em três titulares específicos, os quais serão apresentados sob o viés de dimensões conforme relacionado por parte da doutrina de apoio, quais sejam: a dimensão intrageracional, dimensão intergeracional, e a dimensão interespécies.

\subsection{Dimensão Intrageracional}

A dimensão intrageracional mantém o seu foco nas populações contemporâneas, preocupando-se com a justa distribuição do espaço ambiental com o equilíbrio ecológico. Por meio de uma preocupação especial com os pobres, procura pautar-se com base no princípio da igualdade das partes, onde todos os seres humanos possuem direitos a uma justa distribuição dos recursos naturais, cabendo um desfrute igualitário dos direitos sobre o patrimônio natural.

Sobre esta dimensão, aponta Rogério Rammê:

Isso porque é nessa dimensão que as considerações sobre justiça voltam-se para as disparidades na apropriação dos recursos naturais do planeta; para a relação existente entre pobreza e meio ambiente; para a desigualdade na distribuição do espaço ambiental ecologicamente equilibrado e das externalidades ambientais negativas; sempre tendo como destinatárias as gerações humanas contemporâneas. (RAMMÊ. 2012, p.131)

O viés intrageracional aborda o princípio da solidariedade e o princípio de partes iguais, para que cada indivíduo tenha direito a igual acesso nos recursos naturais existentes no planeta. A distribuição dos recursos ambientais não deve estar vinculada ao poderio econômico ou aos traços capitalistas predominantes, mas deve partir da premissa de que todo indivíduo em qualquer lugar do planeta, faz jus a gozar dos recursos ambientais disponíveis.

Há que se apresentar ainda a dimensão intrageracional, sob o aspecto ético/filosófico, pontuado por Ricardo Waldman, que apresenta a dimensão intrageracional, por meio do relacionamento do ser humano com outro ser humano, ligada por conceitos de ética e alteridade.

O encontro de um ser humano com outro é mais pleno do que o anteriormente mencionado porque temos linguagem e, logo, resposta. Deste encontro segue-se: Não matarás (Êxodo 20, 13). Temos, aqui também, responsabilidade, pois não podemos dominar, abusar do outro e aí vem a necessidade da justiça, que estabelece bases de uma vida em que as necessidades de sobrevivência são satisfeitas e a busca de uma vida plena pode ser satisfeita. A ausência de condições econômicas coloca o sujeito à mercê da dominação por outro, impede o agir responsável. A atribuição de direitos é uma técnica racional que exige comparação entre os incomparáveis 'Outros', necessária à implementação desta responsabilidade e que implica na assunção de uma relação Eu-Isso entre seres humanos. (WALDMAN. 2010, p.119) 
Ainda nesta vertente Klaus Bosselman propõe uma substituição de paradigma, propondo a substituição do homem econômico ocidental "homo oeconomicus occidentalis" pela figura do homem ecológico universal "homo ecologicus universalis", que a seguir se transcreve:

\begin{abstract}
If we assume that modern legal traditions tend to favour the freedom of homo oeconomicus occidentalis, we can also imagine the freedom of an enlightened homo ecologicus universalis. This type differs from the reductionist Ego of Western provenience as it asserts a connection with its global and natural environment. The real prospect of homo ecologicus universalis may be less important than the very thought of it. Such an image may be helpful to explain the growing number of people who see themselves not in competition, but solidarity with each other. More and more people think of themselves not just as citizens of particular countries, but citizens of the planet (BOSSELMAN. 2004, p. 65) ${ }^{6}$.
\end{abstract}

A justiça ambiental, aplicada aos destinatários intrageracionais, deve superar uma visão local ou nacionalista, para o fim de compreender que todos os indivíduos devem ser considerados em si mesmo e no direito que lhe assiste ao usufruto dos recursos ambientais. A busca por este equilíbrio deve ser já no cenário atual, buscando promover o justo equilíbrio entre bônus e ônus na seara ambiental.

É com estes titulares que deve ser empregado o maior número de ações sociais que visem promover acesso aos direitos sociais e ambientais, com vistas a garantir que esta população que atualmente habita o planeta, encontre-se em condições de preocupar-se com os encargos ambientais das gerações que estão por vir.

\title{
3.2 Dimensão Intergeracional
}

Os movimentos de justiça ambiental preocupam-se não somente com as populações contemporâneas, mas também com as gerações futuras. As gerações vindouras passam a ser consideradas como sujeitos de direitos ambientais, respeitando-se o direito de que as futuras gerações possam usufruir dos recursos ambientais. Neste caminho, Ingo Sarlet e Tiago Fensterseifer apresentam a dignidade humana como vetor fundamental para a garantir a justiça ambiental para as futuras gerações:

\footnotetext{
${ }^{6}$ BOSSELMAN. Klaus. In search for global law: the signifcance of the Earth charter. [Tradução] "Se assumirmos que a tradição legal moderna vem favorecendo a liberdade do Homo oeconomicus occidentalis, podemos também imaginar que houve uma promoção da liberdade do homo ecologicus universalis. Esses tipos se diferem no reducionismo do ego ocidental, eis que afirma uma conexão entre o realidade global e a ambiental, pois a verdadeira perspectiva do homo ecologicus universalis pode ser menos importante do que o próprio pensamento dele. Essa imagem pode ser útil para explicar o crescente número de pessoas que se vêem não competindo, mas sim solidárias umas com as outras. Mais e mais pessoas pensam em si mesmas não apenas como cidadãos de determinados países, mas também como cidadãos do planeta."
} 


\begin{abstract}
Pode ser dizer que a dignidade humana fundamenta tanto a sociedade já constituída quanto a sociedade do futuro, apontando para deveres e responsabilidades das gerações presentes para com as gerações futuras, em que pese - e também por isso mesmo - a herança negativa em termos ambientais legada para as gerações passadas. Tal situação se dá em razão de que a proteção ambiental objetiva garantir condições ambientais favoráveis ao desenvolvimento da vida humana em patamares de dignidade não apenas para as gerações que hoje habitam a Terra e usufruem dos recursos naturais, mas salvaguardando tais condições também para as gerações que irão habitar a Terra no futuro. (SARLET e FENSTERSEIFER. 2013, p.52)
\end{abstract}

A comunidade humana global deve ser vista como um elo entre gerações passadas, atuais e vindouras, o que justifica a preocupação antecipada com as que ainda estão por vir e com a realidade ambiental com que irão se deparar no planeta em virtude do esgotamento dos recursos ambientais. Neste contexto, Rogério Rammê coloca então as futuras gerações no denominado rol dos justiciáveis:

Nela as considerações de justiça ambiental pautam-se pelas relações entre os seres humanos vivos e as gerações humanas futuras. Há, pois, uma ampliação do círculo da comunidade humana numa escala temporal evolutiva, voltada para o futuro da humanidade. Aqui, as futuras gerações passam a integrar o rol dos justiciáveis, ou seja, dos destinatários das considerações de justiça ambiental. (RAMMÊ. 2012, p. 132)

A proposta da equidade intergeracional está direcionada àquelas gerações humanas que ainda não existem, abarcadas por uma expectativa de vida. Proteger esta categoria de indivíduos pressupõe que, daqui a cinquenta ou cem anos, os próximos habitantes possam desfrutar e usufruir dos recursos naturais atualmente existentes. A teoria desenvolvida é inovadora, porquanto, pretende preservas espécies animais e vegetais, bem como a qualidade do ar, água e recursos terrestres para que as próximas gerações possam conhecê-las e gozá-las, tais como estão disponíveis em nossos dias atuais, estando as futuras gerações reconhecidas como sujeitos de direitos (KISS. 2005, p. 54/55).

A equidade intergeracional cuida-se de uma teoria incorporada em diversos instrumentos legais em todo o mundo, visando promover a igualdade de acesso aos recursos naturais às gerações vindouras. Esta teoria parte da concepção de que as atuais gerações que habitam o planeta terra, não estão em nível hierárquico superior aos habitantes ainda não nascidos, cabendo, portanto, o dever de uso racional e sustentável dos recursos ambientais, de maneira a garantir a sua existência às futuras gerações.

\title{
3.3 Dimensão Interespécies
}


A dimensão interespécies integra os demais seres vivos não humanos como sujeitos da justiça ambiental. Trata-se do respeito humano pelas demais formas de vida e ecossistemas, permitindo sua integridade e manutenção. Tal dimensão não é acolhida com facilidade pelos governos ou pelas grandes empresas. Todavia, é considerada o elo entre as duas dimensões anteriores, por indicar que a preservação ambiental a ser resguardada para as futuras gerações compreende a variedade de espécies existentes, não se reduzindo aos avanços tecnológicos e sociais. Nesse sentido, aponta Ingo Sarlet e Tiago Fensterseifer:

\begin{abstract}
Os animais não humanos, diante de tal entendimento, não são protegidos apenas em razão da saúde ou da qualidade de vida do ser humano, mas também em virtude de representarem um valor em si mesmo digno de tutela, suplantando, portanto, a perspectiva do interesse exclusivamente humano para justificar sua proteção jurídica. (SARLET e FENSTERSEIFER. 2013, p.89)
\end{abstract}

Esta dimensão denominada de dimensão biosférica é apresentada por Rogério Rammê como sendo uma das mais relevantes, uma vez que consegue demonstrar o quanto pode ser ampliada as noções de justiça ambiental para além dos interesses exclusivamente humanos. Nessa mesma linha, o posicionamento de Ingo Sarlet e Tiago Fensterseifer:

\begin{abstract}
Nesse contexto, procura-se refletir sobre a reformulação do conceito kantiano (antropocêntrico e individualista) de dignidade, ampliando-o para contemplar o reconhecimento da dignidade para além da vida humana, ou seja, para incidir também em face dos animais não humanos, bem como de todas as formas de vida de um modo geral, à luz de uma matriz jusfilosófica biocêntrica (ou ecocêntrica) capaz de reconhecer a teia da vida que permeia as relações entre ser humano e Natureza. (SARLET e FENSTERSEIFER. 2013, p.53)
\end{abstract}

É necessário cuidado para evitar equívocos com a apresentação da dimensão interespécies. Eis que não se está propagando radicalismos ou equiparação entre a vida humana, animal e vegetal, mas sim, a necessidade de proteção integral a todas as formas de vida existentes, conforme pontuado por Alexandre Kiss:

\begin{abstract}
Não se trata de proteger a qualquer preço todo ser vivo, todo indivíduo, toda espécime, mas toda forma de vida: pode-se matar um mosquito, mas a espécime, em si mesma, tem seu lugar no sistema ecológico global. É assim que falamos da necessidade de salvaguardar a diversidade das espécies, quer dizer, da biodiversidade, doravante protegida pela Convenção sobre a Diversidade Ecológica de 5.7.1992. O conceito de justiça para com as outras espécies pode servir de fundamento ético para a aplicação destas normas. (KISS. 2005, p.55)
\end{abstract}

A compreensão de que a justiça ambiental também deve se direcionar para a proteção das demais formas de vida, é uma construção realizada de forma gradual com a finalidade de 
evidenciar que o respeito pela vida em todas as suas peculiaridades, está diretamente relacionada a existência humana, tal como salientado por Ricardo Waldman (2010, p. 118): "Mesmo o mundo vegetal nos diz algo, que ele está lá, que é vida, independente e ao mesmo tempo interdependente com relação à nossa vida".

Há que se considerar que até mesmo diplomas jurídicos têm encampado esta vertente, como é o caso da Constituição Federal brasileira, que preconiza, em seu art. $225, \S 1^{\circ}$, inciso VII, a proibição de práticas que provoquem extinção de espécies ou promovam crueldade aos animais. Sobre essa valoração adotada pelo Estado, convém salientar o exposto por Ingo Sarlet e Tiago Fensterseifer:

Os valores fundamentais da nossa comunidade estatal (dignidade, liberdade, igualdade e solidariedade) devem, necessariamente, ser ampliados para além do espectro humano, no intuito de alcançarmos um patamar moral e cultural mais evoluído, o que, à luz das formulações levantadas, se revela também por meio do reconhecimento e consequente proteção e promoção da dignidade dos animais e da vida de um modo geral ${ }^{7}$. (SARLET e FENSTERSEIFER, 2013, p. 100)

A evolução natural de uma sociedade deve, pois, ser compreendida não somente na maneira em que atribuem direitos aos seres humanos enquanto semelhantes, mas também por meio dos instrumentos de proteção e a valoração atribuída as demais formas de vida. Vida esta que deve ser considerada de forma autônoma, desvinculada então de sua utilidade à raça humana.

Observa-se que a teoria da justiça ambiental não se limita a somente um grupo específico de titulares a serem beneficiados com a distribuição igualitária do acesso aos recursos ambientais. Os movimentos por justiça ambiental atuam de forma integradora, visando abarcar a proteção das sociedades que atualmente povoam o planeta, estas consideradas na dimensão intrageracional.

Mas destina-se também a primar pela proteção dos recursos naturais para as gerações humanas que estão por vir, consistindo em uma vertente de proteção às futuras gerações, assim compreendidas como a dimensão intergeracional. Visando ainda uma integração entre todos os destinatários da justiça ambiental, a teoria expande seu raio de proteção, para considerar, ainda, outras formas de vida que merecem proteção, vidas estas que não são equiparadas à vida humana, mas que também merecem a tutela do Estado, consistente na dimensão interespécies.

\footnotetext{
${ }^{7}$ SARLET. Ingo Wolfganf. FENSTERSEIFER. Tiago. Op cit. p. 100.
} 


\section{CONSIDERAÇÕES FINAIS}

A teoria de justiça ambiental consolidou o desenvolvimento desta pesquisa, pois por meio dela é possível verificar que o acesso igualitário aos bens ambientais devem ser tutelados de forma igualitária, permitindo que todos os indivíduos possam usufruir de variados recursos naturais, dentre eles: água, terra, alimentação saudável, uso do solo, moradia.

A justiça ambiental deve caminhar de forma paralela à promoção dos direitos sociais, permitindo que todos os cidadãos possam usufruir de um meio ambiente equilibrado, ainda que em condições econômicas distintas. O desequilíbrio na distribuição dos bônus e ônus ambiental conduz à chamada injustiça ambiental, onde determinada parcela da população estaria sujeita a condições ambientais precárias, como a água contaminada, ocupação do solo em áreas de risco (encostas, morros, áreas alagáveis, aterros sanitários), ausência de saneamento básico, dentre outros.

É possível verificar que tais deficiências são predominantes em áreas povoadas por pessoas de baixa renda em determinados países como o Brasil, ou ainda, associadas à fatores étnicos-raciais e econômicos, como se apurou ocorrer nos Estados Unidos, por exemplo.

A tutela da justiça ambiental foi planejada com fito de alcançar variados grupos de beneficiários, dentre eles: a sociedade atual (intrageracional), pois percebe diretamente os benefícios do equilíbrio ambiental em todas as camadas sociais da população. As futuras gerações (viés intergeracional), permitindo que as próximas gerações possam gozar de um maior rol de direitos socioambientais já consolidados. E, a proteção interespécies, que se estenderia para além do ser humano, abarcando outras espécies vivas, partindo da concepção de que as demais formas de vida não humanas também merecem ser protegidas sob a ótica da justiça ambiental, pois também compõe a biodiversidade. 


\section{REFERÊNCIAS}

ACSELRAD, Henri. Justiça ambiental e construção social do risco. In: Desenvolvimento e Meio Ambiente, n. 5, Editora UFPR, jan/jun. 2002, p. 49-60.

Henri; MELLO, Cecília Campello do A; BEZERRA, Gustavo das Neves. O que é justiça ambiental. Rio de Janeiro: Garamond, 2009.

AQUINO. Mahalia Gomes de Carvalho. Espaço urbano e saneamento básico: uma discussão pautada na "equidade geográfica". Anais do VIII Congresso Brasileiro de Geógrafos - ISBN: 978-85-98539-04-1. Vitória/ES, 2014.

ARZABE. Patrícia Helena Massa. Pobreza, exclusão social e direitos humanos: o papel do estado. Acesso em 30 de novembro de 2015, às 10h17min. Disponível em:

<http://www.dhnet.org.br/direitos/dhesc/phelena.html>

BAGGIO, Roberta Carmineiro. Justiça ambiental entre redistribuição e reconhecimento: a necessária democratização da proteção ambiental. Lumen Juris: Rio de Janeiro, 2014.

BOSSELMAN, Klaus. In search for global law: the signifcance of the Earth charter. In: Worldviews: Global Religions, Culture, and Ecology, Issue 1, 2004, pages 62-75. 8 v. Disponível em:

<http://earthcharter.org/invent/images/uploads/Klaus\%20B\%5C's\%20article\%20In\%20search $\% 20$ for\%20Global\%20Law.pdf>.Acesso em:11 out. 2016.

BRASIL. Constituição (1988). Constituição da República Federativa do Brasil. Brasília, DF: Senado federal, 1988. Acesso em 10 de setembro de 2018, às 20h55min. Disponível em:

<http://www.planalto.gov.br/ccivil_03/constituicao/ConstituicaoCompilado.htm>

HERCULANO, Selene. Justiça ambiental: de Love Canal à Cidade dos Meninos, em uma perspectiva comparada. In: MELLO, Marcelo Pereira de (Org.). Justiça e sociedade: temas e perspectivas. São Paulo: LTr, 2001. p. 215-238.

SARLET. Ingo Wolfganf. FENSTERSEIFER. Tiago. Direito constitucional ambiental: constituição, direitos fundamentais e proteção do ambiente. 3 ed. São Paulo: Revista dos Tribunais: 2013.

KISS, Alexandre. Justiça ambiental e religiões cristãs. In: PRADO, Ines Virginia; AKEMI, Sandra; SILVA, Solange Teles da. Desafios do direito ambiental do século XXI: estudos em homenagem a Paulo Affonso Leme Machado. São Paulo: Malheiros, 2005.

MARTÍNEZ, Alíer Juan. O ecologismo dos pobres: conflitos ambientais e linguagens de valoração. São Paulo: Contexto, 2007.

RAMMÊ. Rogério Santos. Da justiça ambiental aos direitos e deveres ecológicos: conjecturas políticos-filosóficas para uma nova ordem jurídico-ecológica. Caxias do Sul: RS: Educs, 2012. 
ROCHA. Cármen Lúcia Antunes. O princípio da dignidade da pessoa humana e a exclusão social. Acesso em 24 de novembro de 2016, às 14h09min. Disponível em: <http://egov.ufsc.br/portal/sites/default/files/anexos/32229-38415-1-PB.pdf>

SOUZA. Jessé. Ralé brasileira: quem é e como vive. Belo Horizonte: UFMG, 2009.

WALDMAN. Ricardo Libel. Justiça e encontro - a carta da terra em uma perpectiva buberiana. In: Revista do instituto cultural judaico marc chagall. v.2 n.1 (jan-jun) 2010. 